Research Paper

\title{
Systematic Evaluation of Corticosteroid Use in Obese and Non-obese Individuals: A Multi-cohort Study
}

\author{
Mesut Savas1,2, Vincent L. Wester1,2, Sabine M. Staufenbiel1, 2, Jan W. Koper¹, 2, Erica L.T. van den Akker1,3, \\ Jenny A. Visser ${ }^{1,2}$, Aart J. van der Lely ${ }^{1,2}$, Brenda W.J.H. Penninx ${ }^{4}$, Elisabeth F.C. van Rossum ${ }^{1,2,5 \bowtie}$ \\ 1. Obesity Center CGG (Centrum Gezond Gewicht), Erasmus MC, University Medical Center Rotterdam, Rotterdam, The Netherlands; \\ 2. Department of Internal Medicine, division of Endocrinology, Erasmus MC, University Medical Center Rotterdam, Rotterdam, The Netherlands; \\ 3. Department of Pediatrics, Erasmus MC, University Medical Center Rotterdam, Rotterdam, The Netherlands; \\ 4. Department of Psychiatry, VU University Medical Center, Amsterdam, The Netherlands; \\ 5. Lifelines Cohort Study and Biobank, Groningen, The Netherlands. \\ $\square$ Corresponding author: Elisabeth F.C. van Rossum, MD PhD, Internist-endocrinologist / Professor of Medicine, Head of Obesity Center CGG (Centrum \\ Gezond Gewicht). Erasmus MC, University Medical Center Rotterdam, Room D-428. P.O. Box 2040, 3000 CA Rotterdam, The Netherlands. Phone: +31 1070339 \\ 72, Fax: +31 1070347 68, E-mail: e.vanrossum@erasmusmc.nl \\ (c) Ivyspring International Publisher. This is an open access article distributed under the terms of the Creative Commons Attribution (CC BY-NC) license \\ (https://creativecommons.org/licenses/by-nc/4.0/). See http://ivyspring.com/terms for full terms and conditions.
}

Received: 2017.01.16; Accepted: 2017.03.15; Published: 2017.06.13

\begin{abstract}
Background: Although the use of corticosteroids has been linked to high incidence of weight gain, no data are available concerning the differences in corticosteroid use between a diverse obese population and non-obese individuals. The main purpose of this study was to systematically explore the use of corticosteroids in obese subjects compared to non-obese controls. In addition, we also explored self-reported marked weight gain within obese subjects.

Methods: Two hundred seventy-four obese outpatients (median [range] BMI: $40.1 \mathrm{~kg} / \mathrm{m}^{2}$ [30.5-67.0]), and 526 non-obese controls (BMI: $24.1 \mathrm{~kg} / \mathrm{m}^{2}$ [18.6-29.9]) from two different Dutch cohort studies were included. Corticosteroid use at the time of clinic or research site visit for up to the preceding three months was recorded in detail. Medical records and clinical data were evaluated with regard to age and body mass index in relation to corticosteroid use, single or multiple type use, and administration forms.

Results: Recent corticosteroid use was nearly twice as high for obese subjects than for non-obese controls $(27.0 \%$ vs. $11.9 \%$ and $14.8 \%$, both $\mathrm{P}<.001)$. Largest differences were found for use of local corticosteroids, in particular inhaled forms, and simultaneous use of multiple types. Marked weight gain was self-reported during corticosteroid use in $10.5 \%$ of the obese users.

Conclusion: Corticosteroid use, especially the inhaled agents, is higher in obese than in non-obese individuals. Considering the potential systemic effects of also local corticosteroids, caution is warranted on the increasing use in the general population and on its associations with weight gain.
\end{abstract}

Key words: corticosteroids; obesity; adverse effects.

\section{Introduction}

Synthetic corticosteroids are invaluable in the treatment of a wide range of somatic disorders and have shown their value in many physically demanding conditions. Their different administration routes (e.g. topical, inhaled, nasal, ocular, intra-articular, oral, intra-venous) encourage the use of these medications in both local and systemic disorders in which their mitigating effect on inflammation and the immune system is desired. The widespread use of corticosteroids becomes obvious in national surveys since it is prescribed at least 5.8 million times annually in the 17 million-strong Dutch population [1], whereas in the United States prescription numbers reach over 40 million [2]. These numbers may even underestimate the total use when taking into account over the counter sale of 
corticosteroids and the use in alternative medicine, since some of the non-registered herbal creams have been found to contain potent corticosteroids [3, 4]. In regard to oral corticosteroids, its use substantially increased with thirty percent over the past two decades, with a prevalence of current use around 1\% of the population [5-7]. For inhaled corticosteroids, the percentage of users even doubled between 1990 and 1997 in both the United Kingdom and the Netherlands [8].

In addition to their therapeutic effects, corticosteroids are well known to induce a variety of adverse effects affecting virtually all body systems [9, 10]. Corticosteroid users often experience endocrine and metabolic changes, in particular an increase in weight [11]. This is not surprising, since it is known that high cortisol levels can lead to increased appetite, (truncal) fat accumulation, and altered lipid and glucose metabolism [12-14]. Prolonged use, especially of oral corticosteroids, is notorious for inducing hypercortisolism related side effects and is archetypal for exogenous Cushing's syndrome [15]. However, those systemic side effects are not confined to systemic use, but were also found in local use of corticosteroids. In a recent meta-analysis Broersen et al. investigated different characteristics of corticosteroid use and their effects on adrenal suppression. They found that use of nearly all forms of corticosteroids resulted in an increased risk of adrenal insufficiency [16]. The highest numbers were found for intra-articular injections and oral use (absolute risk of $52.2 \%$ and $48.7 \%$, respectively), while similar numbers were also found in patients using multiple administration forms, including combinations of only local corticosteroids. These results indirectly indicate that also local agents result in high systemic corticosteroid exposure and a subsequent suppression of the adrenal gland function due to negative feedback mechanisms, irrespective of the route of administration, and thus potentially lead to weight gain and its cardiometabolic derangements.

Although various studies have shown an increasing effect of corticosteroids on body mass index (BMI), it still remains unknown whether there is a difference in overall corticosteroid use or in use of particular administration forms between obese and non-obese in the general population. Based on the results of the above-mentioned meta-analysis [16] and given the fact that weight gain is one of the most common undesirable effects of corticosteroid use, we hypothesized an overall higher user rate in obese subjects. Hence, in the present study we systematically investigated the use of corticosteroids in an obese outpatient population in comparison to two independent non-obese control cohorts.
Moreover, in the same obese population, we also specifically examined if marked weight gain could be correlated to corticosteroid use.

\section{Subjects and Methods}

\section{Obese subjects}

Two hundred eighty-two obese patients visiting the Obesity Center CGG of the Erasmus Medical Center (Rotterdam, The Netherlands) between June 2011 and September 2015 were initially included. Before visiting the outpatient clinic, which is a multidisciplinary referral center for diagnostic testing and tailored treatment of obesity, all patients were requested to complete an extensive questionnaire regarding factors related to their overweight. With this questionnaire, we obtained data on self-reported marked weight gain, including questions about whether the patient recalled a time period where they experienced a marked increase in weight, and if so, if they suspected any triggering factor for that. The questionnaire also included questions concerning current and previous medication use, including specific questions about the use of corticosteroids. Recent corticosteroid use was defined as use at the time of visit and/or in the preceding three months and was categorized as local (topical, inhaled, nasal, ocular, intra-articular) or systemic (oral/intra-venous) use and as single or multiple type (i.e., combinations of different administration routes) use. All completed questionnaires were scrutinized by experienced physicians and discussed with the patient at the clinic visit in order to avoid incomplete information or misinterpretation of the questions. These questionnaires and electronic medical records, including records of the visit, were also used to assess weight and height. BMI was computed by dividing weight $(\mathrm{kg})$ by height squared $\left(\mathrm{m}^{2}\right)$. Patients in whom the time of corticosteroid use was unknown $(\mathrm{N}=8)$ were excluded from the analyses. Ethical approval was obtained for the present study.

\section{Non-obese controls}

In order to assess the use of corticosteroids in non-obese subjects, we included participants of two different Dutch cohort studies: the Lifelines and the Netherlands Study of Depression and Anxiety (NESDA) cohort.

The Lifelines cohort is a large population-based cohort study from the Northern Netherlands (www.lifelines.nl) [17]. Participants are observed over an extended period of time and are subjected to multiple moments of data and sample collection. One of the collection procedures requires the patients to complete a questionnaire about corticosteroid use in the past three months. For this study, we included a 
sample of 295 participants who had completed this self-report research questionnaire. In these persons, we assessed the same anthropometric features and corticosteroid-related characteristics (yes/no current corticosteroid use, types of administration forms, and single or multiple type use) as in the obese outpatients.

The other control cohort was recruited from NESDA, a large ongoing longitudinal cohort study among adult participants with a current or past psychopathological diagnosis together with healthy controls with no previous psychiatric diseases [18]. Here, we evaluated the clinical data and questionnaires of 355 psychiatrically healthy controls in whom the same research questionnaire as in the Lifelines cohort was collected [19]. In order to minimize recall bias with regard to corticosteroid use, we assessed both completed questionnaires and minutely detailed information about medication use that was checked during each visit at the research site.

For comparative analyses, we excluded participants with underweight $(\mathrm{BMI}<18.50)$ or obesity (BMI $\geq 30.00$ ) from both Lifelines (control group I) and NESDA (control group II) cohorts, which resulted in the exclusion of respectively $60(20.3 \%)$ and 61 (17.2\%) subjects. From the latter group, also three healthy controls were excluded because of inconclusive data on corticosteroid use. Subsequently, a total number of 526 non-obese controls (control group I, $\mathrm{N}=235$; control group II, $\mathrm{N}=291$ ) were enrolled in this study. In order to investigate if there was a relationship between corticosteroid use and age and whether the numbers of recent users between obese and non-obese subjects differed with age, we analyzed the differences between both groups in weighted age-tertiles. This resulted in the classification of persons $<36$ years in the first tertile, $36-49$ years in the second, and $\geq 50$ years in the last tertile.

\section{Statistical analysis}

Statistical analysis was performed with IBM SPPS Statistics version 21 (IBM Corp., Armonk, NY) and GraphPad Prism version 5.01 (GraphPad Software Inc., La Jolla, CA) for Windows. Differences in demographic and clinical characteristics were analyzed using Chi-square tests and ANOVA's, when appropriate. Trend analysis for corticosteroid use in relation to age-tertiles was performed with the Cochran-Armitage test for trend. Logistic regression analyses were conducted for comparative analyses between the obese and the control groups and were adjusted for age and sex as indicated. P-values below 0.05 were considered to indicate statistical significance for all analyses.

\section{Results}

\section{Baseline characteristics}

The demographic and clinical characteristics of the three groups are summarized in Table 1 . The average BMI in the obese group was $40.7 \pm 6.3 \mathrm{~kg} / \mathrm{m}^{2}$ versus $24.7 \pm 2.6$ (control group $\mathrm{I}, \mathrm{P}<.001$ ) and $24.0 \pm 2.8$ $\mathrm{kg} / \mathrm{m}^{2}$ (control group II, $\mathrm{P}<.001$ ) in the non-obese cohorts. All groups consisted primarily of women, with percentages ranging from $64.9 \%$ (control group II) up to $75.2 \%$ (obese group). Obese participants were on average younger compared to control group II ( $41.5 \pm 14.3$ vs. $46.7 \pm 14.9$ years, $\mathrm{P}<.001)$ but were not different in age compared to control group I.

Table 1. Demographic and clinical characteristics of study participants

\begin{tabular}{llllll}
\hline & Obese & \multicolumn{4}{c}{ Non-obese } \\
\cline { 3 - 6 } & & Control group I & $\boldsymbol{P}_{\text {diff }}$ & Control group II & $\boldsymbol{P}_{\text {diff }}$ \\
\hline $\mathrm{N}$ & 274 & 235 & \multicolumn{2}{c}{291} & .008 \\
Sex, n (\%) & & & .347 & & \\
Male & $68(24.8)$ & $67(28.5)$ & & $102(35.1)$ & \\
Female & $206(75.2)$ & $168(71.5)$ & & $189(64.9)$ & \\
Age, years & $41.5(14.3)$ & $42.0(11.7)$ & .662 & $46.7(14.9)$ & $<.001$ \\
BMI, kg/m $\mathrm{m}^{2}$ & $40.7(6.3)$ & $24.7(2.6)$ & $<.001$ & $24.0(2.8)$ & $<.001$ \\
\hline
\end{tabular}

Values are presented as number (percentage) or mean (SD). Differences were analyzed using Chi-square tests and ANOVA's.

\section{Corticosteroid use obese versus non-obese}

In the obese group, $55.8 \%$ of all patients reported having used any form of corticosteroids at any time point. Among the obese subjects, 74/274 (27.0\%) subjects were currently using or had used corticosteroids in the past three months. Among the recent users, the inhaled and nasal agents were most commonly used (Table 2). Asthma, hay fever/rhino(-sinusitis), and psoriasis were the main known indications for corticosteroid use $(25.7 \%, 8.9 \%$, and $7.9 \%$; Table 3). Recent use of corticosteroids in the obese group was significantly higher compared to non-obese from both control cohorts $(11.9 \%, \mathrm{P}<.001$ [control group I] and $14.8 \%, \mathrm{P}<.001$ [control group II]; Figure 1).

Dividing the control groups into two weight classes, i.e. "normal weight" (BMI 18.50-24.99) and "overweight" (BMI 25.00-29.99), and comparing these to the obese subjects still resulted in significant differences regarding the recent use of corticosteroids. Largest differences were observed between normal weight controls from both cohorts and the obese subjects $(\mathrm{P}<.001$ [control group I] and $\mathrm{P}=.001$ [control group II]; Figure 1). 


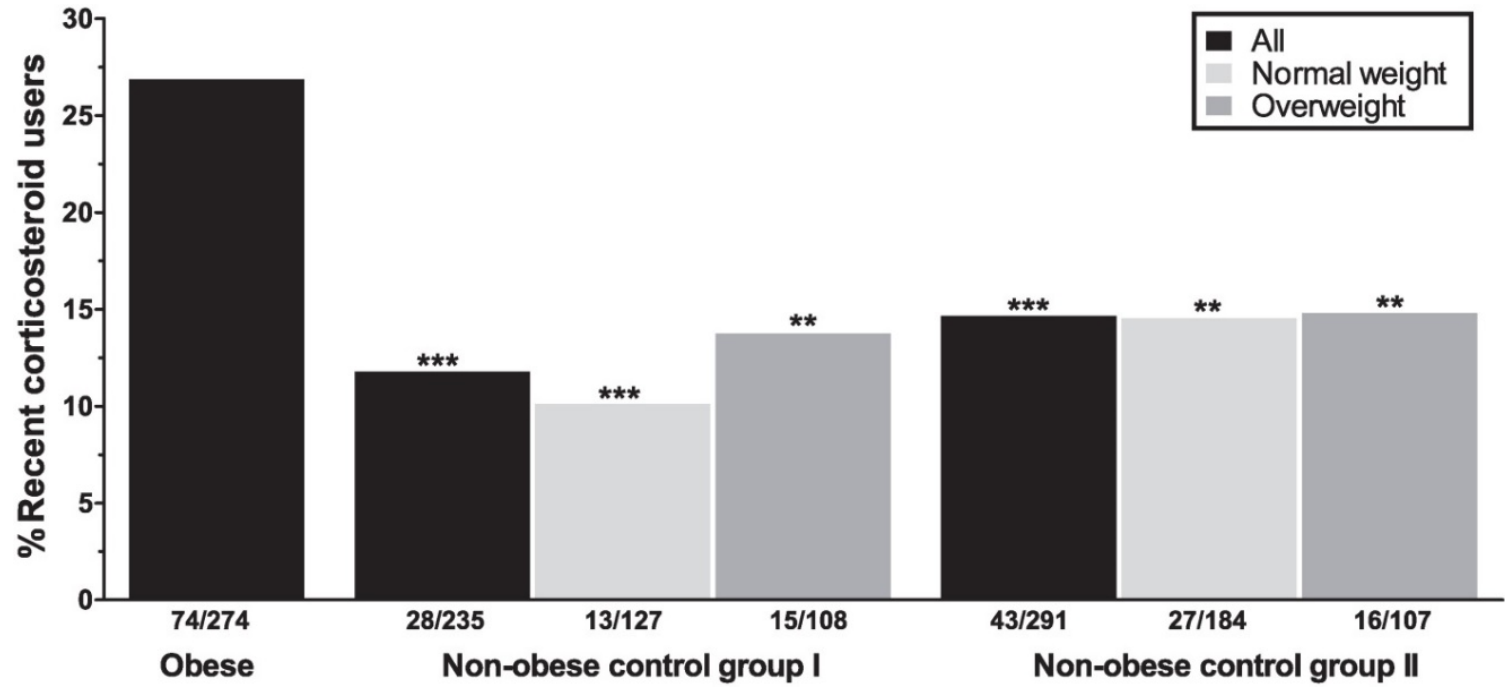

Figure 1. Recent corticosteroid use in obese and non-obese subjects. Analyses between the obese group and the non-obese control groups as a whole (black bars), or stratified for two weight classes (light gray = normal weight, dark gray = overweight) are controlled for sex and age. All asterisks depict P-values for the comparisons with the obese group. $* * \mathrm{P}<.01$, $* * * \mathrm{P}<.001$.

Table 2. Recent use of different corticosteroid administration forms in obese and non-obese individuals

\begin{tabular}{llllll}
\hline & $\begin{array}{l}\text { Obese } \\
\text { (N=274) }\end{array}$ & \multicolumn{5}{c}{$\begin{array}{l}\text { Control group I } \\
\text { (N=235) }\end{array}$} & $\begin{array}{l}\boldsymbol{P}_{\text {diff }} \\
\text { L }\end{array}$ & $\begin{array}{l}\text { Control group II } \\
\mathbf{( N = 2 9 1 )}\end{array}$ & $\boldsymbol{P}_{\text {diff }}$ \\
\hline Local & $70(25.5 \%)$ & $27(11.5 \%)$ & $<.001$ & $38(13.1 \%)$ & $<.001$ \\
Topical & $21(7.7 \%)$ & $11(4.7 \%)$ & .145 & $17(5.8 \%)$ & .323 \\
Inhaled & $38(13.9 \%)$ & $7(3.0 \%)$ & $<.001$ & $11(3.8 \%)$ & $<.001$ \\
Nasal & $23(8.4 \%)$ & $12(5.1 \%)$ & .147 & $15(5.2 \%)$ & .173 \\
Ocular & $3(1.1 \%)$ & $0(0.0 \%)$ & - & $1(0.3 \%)$ & .251 \\
Intra-articular & $3(1.1 \%)$ & $0(0.0 \%)$ & - & $0(0.0 \%)$ & - \\
Systemic & $7(2.6 \%)$ & $2(0.9 \%)$ & .180 & $8(2.7 \%)$ & .631 \\
(oral/i.v.) & & & & & \\
Multiple types & $17(6.2 \%)$ & $4(1.7 \%)$ & .015 & $7(2.4 \%)$ & .038 \\
\hline
\end{tabular}

Values are presented as number (percentage). Differences in use of each corticosteroid administration form between obese patients and the control groups were analyzed separately using logistic regression analyses adjusted for sex and age. Abbreviation: i.v., intra-venous.

Table 3. Indications for recent corticosteroid use in the obese group.

\begin{tabular}{ll}
\hline & Corticosteroid prescriptions (N=101) \\
\hline Asthma, n (\%) & $26(25.7)$ \\
Hay fever/rhino(-sinusitis), n (\%) & $9(8.9)$ \\
Psoriasis, n (\%) & $8(7.9)$ \\
Eczema, n (\%) & $7(6.9)$ \\
COPD, n (\%) & $6(5.9)$ \\
Nasal congestion, n (\%) & $3(3.0)$ \\
Ocular diseases ${ }^{*}$ n (\%) & $3(3.0)$ \\
Auto-immune diseases†, n (\%) & $2(2.0)$ \\
Othersł, n (\%) & $12(11.9)$ \\
Unknown, n (\%) & $25(24.8)$
\end{tabular}

Values are presented as number (percentage). *Includes iridocyclitis, scleritis, and uveitis; †Includes cerebral vasculitis and Crohn's disease; ¥Includes among others alopecia areata, nasal polyps, panhypopituitarism, and renal transplantation.

With regard to age-tertiles, we found significantly higher corticosteroid use in obese subjects for each age group with the smallest difference in the oldest tertile (mean difference per tertile: $14.3 \%, \mathrm{P}=.005$ [first tertile], $15.5 \%, \mathrm{P}=.001$ [second tertile], and $11.4 \%, \mathrm{P}=.039$ [third tertile]; Figure 2). Separate trend analyses showed a significant trend in the non-obese group $\left(\chi^{2}{ }_{1}=4.520\right.$, $\mathrm{P}=.034)$ and no significance in the obese $\left(\chi^{2}{ }_{1}=0.679\right.$, $\mathrm{P}=.410)$.

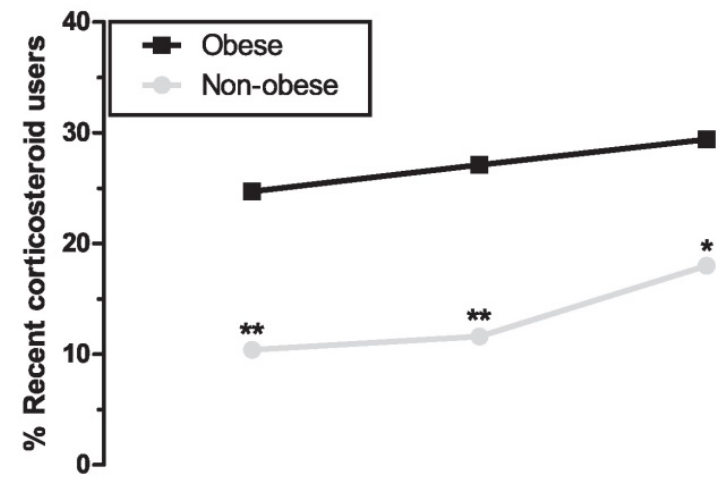

\begin{tabular}{lccc}
\cline { 2 - 3 } & $<36$ yrs & $\mathbf{3 6 - 4 9}$ yrs & $\geq \mathbf{5 0}$ yrs \\
OB $(\mathrm{n} / \mathrm{N})$ & $23 / 93$ & $26 / 96$ & $25 / 85$ \\
NO $(\mathrm{n} / \mathrm{N})$ & $17 / 164$ & $20 / 173$ & $34 / 189$
\end{tabular}

Figure 2. Relation between different age groups and use of corticosteroids. The three age groups represent weighted age-tertiles of obese and the combined non-obese participants from both control groups. Logistic regression analyses between obese and non-obese age groups are adjusted for sex. ${ }^{*} \mathrm{P}<.05$, ${ }^{*} \mathrm{P}<.01$. Abbreviations: $O B$, obese; $N O$, non-obese.

\section{Administration routes of corticosteroids}

In the obese group, the use of local corticosteroids was significantly higher compared to both non-obese controls $(25.5 \%$ vs. $11.5 \%$ [control group I] and $13.1 \%$ [control group II], both $\mathrm{P}<.001$; Table 2). In addition, stratification for the different 
administration routes revealed significantly higher rates for inhaled corticosteroids in the obese subjects. There were, however, no differences in use of the other local corticosteroids or the systemic administration forms.

Use of multiple types of corticosteroids was present in 17 obese patients (6.2\%). This was significantly higher than in the control groups I $(1.7 \%$, $\mathrm{P}=.015)$ and II $(2.4 \%, \mathrm{P}=.038)$. The majority of the multiple type users of both the obese and the non-obese groups were using at least one inhaled corticosteroid (88\% and 73\%, respectively). The combination of inhaled corticosteroids with at least one topical corticosteroid was most common in the obese group (47\%), whereas in the non-obese controls inhaled forms were frequently combined with nasal corticosteroids (55\%; Table 4).

Table 4. Combination of corticosteroids in users of multiple types of corticosteroids.

\begin{tabular}{lll}
\hline & Obese (N=17) & Non-obese (N=11) \\
\hline Inhaled with topical, n (\%) & $5(29)$ & $1(9)$ \\
Inhaled with nasal, n (\%) & $5(29)$ & $4(36)$ \\
Inhaled with topical and nasal, n (\%) & $2(12)$ & $0(0)$ \\
Inhaled with nasal and oral, n (\%) & $1(6)$ & $2(18)$ \\
Topical with nasal, n (\%) & $0(0)$ & $2(18)$ \\
Others, n (\%) & $4(24)$ & $2(18)$ \\
Values are presented as number (percentage) within the group of multiple types \\
users for the obese group and combined non-obese control group.
\end{tabular}

\section{Marked weight gain}

Of the obese subjects who reported recent or ever use of corticosteroids, $10.5 \%$ considered the use of corticosteroids as the underlying cause of a period of marked weight gain. The oral administration form was reported most frequently (12/16 subjects) as the triggering factor, followed by two patients who had previously received corticosteroid injections. Majority of the patients from the former administration form $(67 \%)$ had used or were currently using prednisone for over 3 months continuously, two subjects had been prescribed prednisone for a short-term period ( $<3$ months) and two patients had used it for an unknown duration.

\section{Discussion}

To the best of our knowledge, this is the first study to systematically examine corticosteroid use in a diverse sample of obese and non-obese individuals. Here, we have shown that the use of corticosteroids was significantly higher in obese outpatients when compared to non-obese subjects from two separate control groups. This finding was consistent across all age groups but became less evident in the oldest group. Higher rates of use were primarily found for the local corticosteroids, in particular for the inhaled administration forms. In addition, we also found that a significantly higher percentage of the obese individuals were simultaneously using multiple corticosteroid types in comparison to non-obese subjects. However, no differences were observed with respect to oral corticosteroid use.

Cushing's syndrome is most commonly induced by exogenous corticosteroid administration, typically attributed to (long-term) systemic corticosteroid use, and is frequently accompanied by weight gain [20, 21]. However, the increased risk of occurrence of adrenal insufficiency even with local administration forms [16] shows the importance of surveillance for systemic effects of all administration types. We found that more than half of our obese sample have used corticosteroids at any point in time and that their recent use more often involves multiple administration routes, with the latter been strongly linked to supraphysiological systemic levels of glucocorticoids (based on high absolute risk of adrenal insufficiency) [16]. These findings tend to support our hypothesis that local corticosteroid forms, as being the most common prescribed agents in our obese group, could eventually contribute to amongst others a higher weight and/or a more laborious weight loss. But given the nature of this study, it is not possible to demonstrate temporality and to infer a causal relationship between corticosteroid use and obesity.

Regardless of the fact that in this study we did not assess the effect of corticosteroids on weight gain, physicians should be vigilant for corticosteroid-induced side effects in all patients gaining weight in a short period of time since approximately $10 \%$ of the marked weight gain in the ever corticosteroid users seemed to be preceded by corticosteroid use. In concordance with previous reports by Berthon et al, who showed that weight gain as a result of oral corticosteroids is unlikely in short-term users ( $<3$ months) in contrast to long term users ( $\geq 3$ months) [22, 23], majority of our corticosteroid induced marked weight gainers reported to have used corticosteroids for at least couple of months to several years. The cumulative exposure to corticosteroids seems therefore to be an essential factor in inducing weight changes. Since inhaled corticosteroids are generally prescribed for chronic conditions, and multiple type use most often includes inhaled agents, it is reasonable to hypothesize that these forms more gradually contribute to weight gain. The increasing prevalence of obesity [24] as well as increased corticosteroid use in the past decades $[5,8]$ additionally nourish the idea that corticosteroid use could be a substantial 
contributing factor for overall weight gain in the Western world. This is especially important given the fact that corticosteroids not only promote the accumulation of abdominal fat but also stimulate the appetite for high calorie "comfort" foods [12].

However, the cause-and-effect relationship between corticosteroid use and obesity seems to be bidirectional. Besides the well-known cardiometabolic diseases such as diabetes mellitus, dyslipidemia, and atherosclerosis, obesity has been linked to low-grade inflammation and various immune-mediated conditions $[25,26]$. In the present study, we found that obese patients are using inhaled corticosteroids more frequently, which are mainly prescribed for asthma and chronic obstructive pulmonary disease (COPD). This is in line with literature where both conditions have been linked to higher BMI [27-29]. Interestingly, in a study with asthmatic obese patients, Van Huisstede et al. showed that weight loss after bariatric surgery was associated with improved asthma control and lower systemic inflammation markers [30]. Similar results were found in other studies in which weight loss was associated with less asthmatic symptoms and increased lung function [31, 32]. In addition, weight loss and lower BMI have also been associated with reduced disease severity or better therapeutic response in other immune-related disorders including psoriasis [33, 34], rheumatoid arthritis [35, 36], and ankylosing spondylitis [37, 38]. This emphasizes the mentioned relationship between obesity and inflammation and could be an alternative reason for high corticosteroid use in our obese sample. Another plausible explanation would be that there is not a causal link between these parameters but that other factors, such as a low social-economic status and a pro-inflammatory genetic profile, lead to both obesity and more inflammation subsequently requiring the use of corticosteroids.

Nevertheless, it still remains disputable which of the two directions, i.e. corticosteroid use preceding obesity or vice versa, prevails in clinical practice. Patients with COPD, for instance, commonly present with overweight or obesity [39]. Since corticosteroids are an important part of the medical treatment of COPD, it could be proposed that the overall high BMI in these patients is partly the result of corticosteroid use. Aside from the reverse causality between these characteristics, it would be advisable to screen all obese patients for corticosteroid use. In the case of corticosteroid use, one should reconsider if the use is still necessary and if so, whether an alternative treatment is available. The importance of this can be derived from a previous study in asthmatic obese patients for whom the diagnosis could not be confirmed in $41 \%$ of the cases after extensive pulmonary testing, although $23 \%$ of these patients were still currently using inhaled corticosteroids [40]. In these cases, ceasing of corticosteroids under medical supervision could potentially help in losing weight more easily. Otherwise, patients may succumb to a vicious cycle of weight gain, obesity-related comorbidities, and further corticosteroid need.

One of the strengths of the present study is the use of two different non-obese control groups and the fact that both the study group and the control groups are from the same country. Moreover, the same detailed questionnaire on corticosteroid use was administered in both non-obese cohorts.

An important study limitation worth noting is that information about the dose and duration of corticosteroid use was incomplete and hence not used in this study. Both components are known to play an important role in the accumulative exposure and induction of side effects in corticosteroid users [41]. Nevertheless, medical conditions requiring corticosteroids are most often of a chronic nature and demand corticosteroid use for a longer period of time or at least with frequent intervals. Moreover, various studies have shown that weight gain can also occur in response to relatively low doses of corticosteroids. In a study of more than two thousand long-term corticosteroid users, Curtis et al. have found that weight gain manifested in $70 \%$ of the low-dose systemic users and was indeed the most prevalent self-reported adverse event [11].

In conclusion, corticosteroid use is high in obese individuals who have been referred due to their obesity and common across all ages. High user rates were especially prevalent for inhaled corticosteroids and the simultaneous use of different administration forms. This warrants stricter monitoring of corticosteroid use in obese as these medications can potentially induce weight gain and maintain excess weight. However, large longitudinal prospective cohort studies are needed to specifically determine the individual effect of the different corticosteroid administration forms on weight gain.

\section{Acknowledgments}

The authors are grateful to Karin van der Zwaan and Nancy Knossenburg (both affiliated to Obesity Center CGG, Erasmus MC, University Medical Center Rotterdam, Rotterdam, The Netherlands) for their significant contribution in logistical assistance and inclusion of patients at the Obesity Center CGG. We also wish to gratefully acknowledge the staff of the Lifelines and NESDA cohort studies, the contributing research centers delivering data, and the study participants. 


\section{Funding}

This work was supported by the Thrasher Research Fund (grant number TRF-11643); the Netherlands Brain Foundation (grant number F2011(1)-12); and fellowship from the Erasmus MC. The infrastructure for the NESDA study (www.nesda.nl) is funded through the Geestkracht program of the Netherlands Organization for Health Research and Development (ZonMw, grant number 10-000-1002) and by participating universities (VU University Medical Centre, Leiden University Medical Centre, University Medical Centre Groningen).

\section{Competing Interests}

Penninx has received research funding from Janssen Research. Other authors have declared that no competing interest exists.

\section{References}

1. [Internet] The National Health Care Institute: Diemen, The Netherlands. Genees- en hulpmiddelen Informatie Project (GIP) databank. Revised November 2016. https://www.gipdatabank.nl/databank.asp

2. Hsiao CJ, Cherry DK, Beatty PC, Rechtsteiner EA. National Ambulatory Medical Care Survey: 2007 summary. Natl Health Stat Report. 2010: 1-32.

3. Keane FM, Munn SE, du Vivier AW, Taylor NF, Higgins EM. Analysis of Chinese herbal creams prescribed for dermatological conditions. BMJ. 1999; 318: 563-4.

4. Ramsay HM, Goddard W, Gill S, Moss C. Herbal creams used for atopic eczema in Birmingham, UK illegally contain potent corticosteroids. Archives of Disease in Childhood. 2003; 88: 1056-7.

5. Fardet L, Petersen I, Nazareth I. Prevalence of long-term oral glucocorticoid prescriptions in the UK over the past 20 years. Rheumatology (Oxford). 2011; 50: 1982-90.

6. van Staa TP, Leufkens HG, Abenhaim L, Begaud B, Zhang B, Cooper C. Use of oral corticosteroids in the United Kingdom. QJM. 2000; 93: 105-11.

7. Overman RA, Yeh JY, Deal CL. Prevalence of oral glucocorticoid usage in the United States: a general population perspective. Arthritis Care Res (Hoboken). 2013; 65: 294-8.

8. van Staa TP, Cooper C, Leufkens HG, Lammers JW, Suissa S. The use of inhaled corticosteroids in the United Kingdom and the Netherlands. Respir Med. 2003; 97: 578-85.

9. Buchman AL. Side effects of corticosteroid therapy. J Clin Gastroenterol. 2001; 33: $289-94$.

10. Judd LL, Schettler PJ, Brown ES, Wolkowitz OM, Sternberg EM, Bender BG, et al. Adverse consequences of glucocorticoid medication: psychological, cognitive, and behavioral effects. Am J Psychiatry. 2014; 171: 1045-51.

11. Curtis JR, Westfall AO, Allison J, Bijlsma JW, Freeman A, George V, et al. Population-based assessment of adverse events associated with long-term glucocorticoid use. Arthritis Rheum. 2006; 55: 420-6.

12. Fardet L, Feve B. Systemic glucocorticoid therapy: a review of its metabolic and cardiovascular adverse events. Drugs. 2014; 74: 1731-45.

13. Vegiopoulos A, Herzig S. Glucocorticoids, metabolism and metabolic diseases. Mol Cell Endocrinol. 2007; 275: 43-61.

14. Peckett AJ, Wright DC, Riddell MC. The effects of glucocorticoids on adipose tissue lipid metabolism. Metabolism. 2011; 60: 1500-10.

15. Saag KG, Koehnke R, Caldwell JR, Brasington R, Burmeister LF, Zimmerman $B$, et al. Low dose long-term corticosteroid therapy in rheumatoid arthritis: an analysis of serious adverse events. Am J Med. 1994; 96: 115-23.

16. Broersen LH, Pereira AM, Jorgensen JO, Dekkers OM. Adrenal Insufficiency in Corticosteroids Use: Systematic Review and Meta-Analysis. J Clin Endocrinol Metab. 2015; 100: 2171-80.

17. Scholtens S, Smidt N, Swertz MA, Bakker SJ, Dotinga A, Vonk JM, et al. Cohort Profile: LifeLines, a three-generation cohort study and biobank. Int J Epidemiol. 2015; 44: 1172-80.

18. Penninx BW, Beekman AT, Smit JH, Zitman FG, Nolen WA, Spinhoven P, et al. The Netherlands Study of Depression and Anxiety (NESDA): rationale, objectives and methods. Int J Methods Psychiatr Res. 2008; 17: 121-40.

19. Staufenbiel SM, Penninx BW, de Rijke YB, van den Akker EL, van Rossum EF. Determinants of hair cortisol and hair cortisone concentrations in adults. Psychoneuroendocrinology. 2015; 60: 182-94.

20. Shibli-Rahhal A, Van Beek M, Schlechte JA. Cushing's syndrome. Clin Dermatol. 2006; 24: 260-5.

21. Newell-Price J, Bertagna X, Grossman AB, Nieman LK. Cushing's syndrome. Lancet. 2006; 367: 1605-17.
22. Berthon BS, Gibson PG, McElduff P, MacDonald-Wicks LK, Wood LG. Effects of short-term oral corticosteroid intake on dietary intake, body weight and body composition in adults with asthma - a randomized controlled trial. Clin Exp Allergy. 2015; 45: 908-19.

23. Berthon BS, MacDonald-Wicks LK, Wood LG. A systematic review of the effect of oral glucocorticoids on energy intake, appetite, and body weight in humans. Nutr Res. 2014; 34: 179-90.

24. Ng M, Fleming T, Robinson M, Thomson B, Graetz N, Margono C, et al. Global, regional, and national prevalence of overweight and obesity in children and adults during 1980-2013: a systematic analysis for the Global Burden of Disease Study 2013. Lancet. 2014; 384: 766-81.

25. Cox AJ, West NP, Cripps AW. Obesity, inflammation, and the gut microbiota. Lancet Diabetes Endocrinol. 2015; 3: 207-15.

26. Kanneganti TD, Dixit VD. Immunological complications of obesity. Nat Immunol. 2012; 13: 707-12

27. Camargo CA, Jr., Weiss ST, Zhang S, Willett WC, Speizer FE. Prospective study of body mass index, weight change, and risk of adult-onset asthma in women. Arch Intern Med. 1999; 159: 2582-8.

28. Ronmark E, Andersson C, Nystrom L, Forsberg B, Jarvholm B, Lundback B. Obesity increases the risk of incident asthma among adults. Eur Respir J. 2005; 25: 282-8.

29. Franssen FM, O'Donnell DE, Goossens GH, Blaak EE, Schols AM. Obesity and the lung: 5. Obesity and COPD. Thorax. 2008; 63: 1110-7.

30. van Huisstede A, Rudolphus A, Castro Cabezas M, Biter LU, van de Geijn GJ, Taube C, et al. Effect of bariatric surgery on asthma control, lung function and bronchial and systemic inflammation in morbidly obese subjects with asthma. Thorax. 2015; 70: 659-67.

31. Maniscalco M, Zedda A, Faraone S, Cerbone MR, Cristiano S, Giardiello C, et al. Weight loss and asthma control in severely obese asthmatic females. Respir Med. 2008; 102: 102-8.

32. Stenius-Aarniala $B$, Poussa $T$, Kvarnstrom I, Gronlund EL, Ylikahri $M$, Mustajoki P. Immediate and long term effects of weight reduction in obese people with asthma: randomised controlled study. BMJ. 2000; 320: 827-32.

33. Jensen P, Zachariae C, Christensen R, Geiker NR, Schaadt BK, Stender S, et al. Effect of weight loss on the severity of psoriasis: a randomized clinical study. JAMA Dermatol. 2013; 149: 795-801.

34. Gisondi P, Del Giglio M, Di Francesco V, Zamboni M, Girolomoni G. Weight loss improves the response of obese patients with moderate-to-severe chronic plaque psoriasis to low-dose cyclosporine therapy: a randomized, controlled, investigator-blinded clinical trial. Am J Clin Nutr. 2008; 88: 1242-7.

35. Heimans L, van den Broek M, le Cessie S, Siegerink B, Riyazi N, Han KH, et al. Association of high body mass index with decreased treatment response to combination therapy in recent-onset rheumatoid arthritis patients. Arthritis Care Res (Hoboken). 2013; 65: 1235-42.

36. Ottaviani S, Gardette A, Tubach F, Roy C, Palazzo E, Gill G, et al. Body mass index and response to infliximab in rheumatoid arthritis. Clin Exp Rheumatol. 2015; 33: 478-83.

37. Ottaviani S, Allanore Y, Tubach F, Forien M, Gardette A, Pasquet B, et al. Body mass index influences the response to infliximab in ankylosing spondylitis. Arthritis Res Ther. 2012; 14: R115.

38. Gremese E, Bernardi S, Bonazza S, Nowik M, Peluso G, Massara A, et al. Body weight, gender and response to TNF-alpha blockers in axial spondyloarthritis. Rheumatology (Oxford). 2014; 53: 875-81.

39. O'Donnell DE, Ciavaglia CE, Neder JA. When obesity and chronic obstructive pulmonary disease collide. Physiological and clinical consequences. Annals of the American Thoracic Society. 2014; 11: 635-44.

40. van Huisstede A, Castro Cabezas M, van de Geijn GJ, Mannaerts GH, Njo TL Taube C, et al. Underdiagnosis and overdiagnosis of asthma in the morbidly obese. Respir Med. 2013; 107: 1356-64.

41. McDonough AK, Curtis JR, Saag KG. The epidemiology of glucocorticoid-associated adverse events. Curr Opin Rheumatol. 2008; 20: $131-7$. 